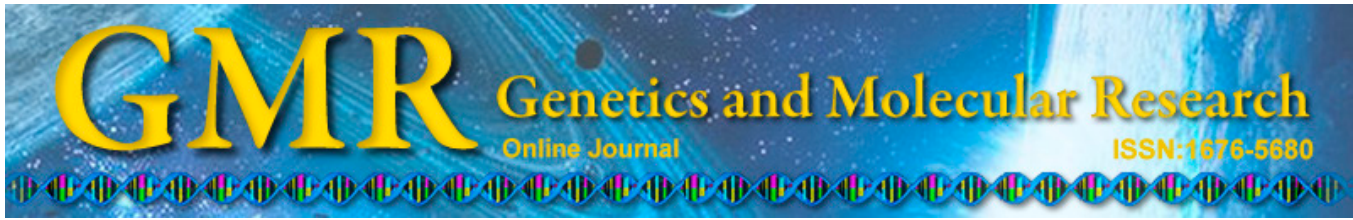

\title{
Association of Hsp60 expression with damage to rat myocardial cells exposed to heat stress in vivo and in vitro
}

\author{
Y.F. Cheng ${ }^{1}$, J.R. Sun ${ }^{1}$, H.B. Chen ${ }^{1}$, A. Abdelnasir ${ }^{1}$, S. Tang ${ }^{1}$, N. Kemper ${ }^{2}$, \\ J. Hartung ${ }^{2}$ and E.D. Bao ${ }^{1}$ \\ ${ }^{1}$ College of Veterinary Medicine, Nanjing Agricultural University, \\ Nanjing, China \\ ${ }^{2}$ Institute for Animal Hygiene, Animal Welfare and Farm Animal Behaviour, \\ University of Veterinary Medicine Hannover, Foundation, Hannover, Germany \\ Corresponding author: E.D. Bao \\ E-mail: b_endong@njau.edu.cn
}

Genet. Mol. Res. 13 (4): 9371-9381 (2014)

Received September 24, 2013

Accepted January 13, 2014

Published November 11, 2014

DOI http://dx.doi.org/10.4238/2014.November.11.3

\begin{abstract}
To investigate the protective role of Hsp60 against stress damage and its role in the sudden death of stressed animals, changes in the levels of Hsp60 protein and hsp 60 mRNA of myocardial cells in vivo and in vitro were studied. In addition, the relationship between Hsp60 expression and heat-induced damage was also studied. Rats were exposed to a temperature of $42^{\circ} \pm 1^{\circ} \mathrm{C}$ for $0,20,40,60,80$, or $100 \mathrm{~min}$. More than $50 \%$ of the rats died suddenly within $100 \mathrm{~min}$. With increasing heat stress duration, hsp60 mRNA levels significantly increased in both in vivo and in vitro rat myocardial cells; however, a similar trend was not observed for Hsp60 protein levels. Although the changes observed in Hsp60 expression in myocardial cells in vitro were inconsistent with those of rat heart tissues in vivo, Hsp60 expression levels were consistent with the histopathological damage observed in myocardial cells both in vivo and in vitro. Differences in Hsp60 expression may reflect the degree of injury sustained by myocardial cells in vivo and in vitro. As a mitochondrial protein, Hsp60
\end{abstract}


represents a potential biomarker of heat stress, and may protect against heat stress induced myocardial cellular damage both in vivo and in vitro.

Key words: Hsp60; Myocardial cell; Heat stress; Rat; In vivo and in vitro cell culture

\section{INTRODUCTION}

Heat stress may lead to large economic losses in animal husbandry, because food consumption, growth rate, feeding efficiency, and survival all decline when the environmental temperature increases (van der Hel et al., 1992). Chronic heat exposure and heat stress are of increasing concern in animal production in countries with hot climates, as well as in countries with temperate climates, due to reduced growth performance (Geraert et al., 1996). In chickens, high temperatures may cause shock and sudden death from organ failure, mostly as a consequence of heart failure preceded by cardiovascular damage (Lee et al., 1996). However, eukaryotic cells have an intrinsic mechanism to defend themselves against external stressors. This defense mechanism probably evolved from a group of chaperone proteins, the heat shock proteins (Hsps) (Snoeckx et al., 2001). Research showed that Hsps are important endogenous protective proteins that play a significant role in the cellular response to stress (Gullo and Teoh, 2004).

Hsps are ubiquitously expressed and highly conserved in both prokaryotes and eukaryotes. They are classified into many families according to their molecular size, including the small HSPs, HSP70, and HSP90 (Tissiéres et al., 1974). There is growing evidence that Hsps are constitutively expressed under normal conditions, and act as molecular chaperones, preventing the misfolding and aggregation of proteins under conditions of cellular stress in both prokaryotic and eukaryotic cells (Bukau and Horwich, 1998). Hsp levels are increased by stress, including environmental, physical, chemical and transport (Barisic and Kopic, 2002). In addition, Hsps exhibit a protective role during pathologic processes (Walter and Buchner, 2002).

Hsp60, also known as GroEL in prokaryotes, is essential for cell survival under all conditions (Fayet et al., 1989), and plays an important role as a molecular chaperone under heat stress (Ewalt et al., 1997). There is evidence that Hsp60 is a biomarker of angiocardiopathy. Circulating Hsp60 might be involved in the induction/progression of both hypertension and atherosclerosis, as well as being a marker for early cardiovascular disease (Pockley et al., 2000). The abnormal transport of Hsp60 to the cell surface may be an early trigger for myocyte loss, and the progression of heart failure (Lin et al., 2007). Hence, Hsp60 serum levels could be valuable as predictors of cardiovascular risk in preventing pathologic episodes and managing patients at all stages of illness (Rizzo et al., 2012).

Research remains limited about the expression of Hsp60 in mammalian myocardial cells following hyperthermia, either in vivo or in vitro. Thus, this study aimed to investigate the correlation between changes in Hsp60 and its mRNA, and the relationship between Hsp60 expression and heat induced cellular damage in myocardial cells in vivo and in vitro.

\section{MATERIAL AND METHODS}

\section{In vivo model of heat stress in rats}

Sixty adult Sprague Dawley (SD) rats, purchased from Qinglongshan, Nanjing, China, 
were divided randomly into 6 groups, each containing 10 rats. After 3 days of acclimation to being fed at room temperature (RT), all animals were suddenly placed in a controlled-climate chamber (RX8-500D; New Jiangnan Co. Ltd.) and exposed to $42^{\circ} \pm 1^{\circ} \mathrm{C}$ for 0 min (control), $20,40,60,80$, or $100 \mathrm{~min}$. The rats were then humanely killed by decapitation. Heart tissue samples were collected and divided into 2 parts; 1 part was fixed in $10 \%$ neutral buffered formalin for histopathology, while the other part was stored in liquid nitrogen for biological analysis. The study protocol was reviewed and approved by the institutional Animal Care and Use Committee, and the experiment was conducted in accordance with the guidelines of the regional Animal Ethics Committee.

\section{In vitro model of heat stress in rat myocardial cells}

Cells of the H9c2 line, purchased from the American Type Culture Collection, were maintained in Dulbecco's modified Eagle's medium (11995-065; Gibco, Billings, MT, USA) plus $10 \%$ fetal bovine serum (16141079; Gibco) and penicillin/streptomycin (Sigma-Aldrich, St Louis, MO, USA) in a humidified atmosphere of $5 \% \mathrm{CO}_{2}$ and $95 \%$ air at $37^{\circ} \mathrm{C}$. When the cells covered $90 \%$ of the culture plates, the cultures were divided into 6 groups: 1 control group and 5 groups exposed to heat stress for 20, 40, 60, 80, or $100 \mathrm{~min}$. Exposure to heat stress was achieved by quickly transferring the temperature-stress groups into an incubator with a humidified atmosphere of $5 \% \mathrm{CO}_{2}$ and $95 \%$ air at $42^{\circ} \pm 1^{\circ} \mathrm{C}$.

\section{Histopathology and cytopathology}

Heart tissues were fixed in paraformaldehyde after heat stress, then embedded in paraffin and sliced serially into $4-\mu \mathrm{m}$-thick sections. The sections were stained with hematoxylin and eosin, using routine methods, and examined by light microscopy.

H9c2 cells (2-8 x $10^{4}$ cells on $35-\mathrm{mm}^{2}$ plates) grown on coverslips coated with polylysine were fixed with $95 \%$ ethanol solution for $15 \mathrm{~min}$ at RT, and then fixed in $100 \%$ ethanol for $15 \mathrm{~min}$. After three 5-min washes with phosphate buffered saline (PBS), the coverslips were placed in hematine for $2 \mathrm{~min}$ and then washed under running water for $15 \mathrm{~min}$ and soaked in eosin for 2 min. After washing with PBS again, the coverslips were dehydrated and mounted. Stained H9c2 cells were observed under a microscope.

\section{Semiquantitative analysis of Hsp60 expression in vivo and in vitro by Western blotting}

Total proteins from heart tissues in vivo and $\mathrm{H} 9 \mathrm{c} 2$ myocardial cells in vitro from both the control groups and the heat stressed groups were extracted by lysate radio-immunoprecipitation and ultrasound, respectively. Total protein concentrations were determined using a Micro BCA assay kit (232235, Micro BCA ${ }^{\mathrm{TM}}$ Protein Assay Kit; Thermo, China). Thirty microgram samples of $\mathrm{H} 9 \mathrm{c} 2$ cell protein extract or $80 \mu \mathrm{g}$ samples of heart protein extract were separated on 5\% sodium dodecyl sulfate (SDS) polyacrylamide spacer gel $(60 \mathrm{~V}, 30 \mathrm{~min})$ and $12 \%$ SDS separation gel $(100 \mathrm{~V}, 1.5 \mathrm{~h})$, and then transferred onto nitrocellulose membranes by electrotransfer $(200 \mathrm{~mA}, 1 \mathrm{~h})$. The membranes were washed 4 times in washing buffer [ $20 \mathrm{mM}$ Tris base, $\mathrm{pH} 7.6,12.5 \mathrm{mM} \mathrm{NaCl}$ and $0.5 \%$ Tween-20 (TBST buffer)] and blocked with $5 \%$ non-fat milk in Tris-buffered saline (20 mM Tris- $\mathrm{HCl}, \mathrm{pH} 7.6,137 \mathrm{mM} \mathrm{NaCl})$ containing $0.1 \%$ 
Tween-20 (TBST) for $1 \mathrm{~h}$ at RT. The membranes were then incubated with anti-rat monoclonal antibody against Hsp60 (ab13532; Abcam, Cambridge, UK) at a dilution of 1:20,000 and antirat GAPDH monoclonal antibody (ab8224; Abcam) at a dilution of $1: 1000$ for $1 \mathrm{~h}$ at $37^{\circ} \mathrm{C}$. After washing with TBST, the membranes were further incubated with peroxidase-conjugated second antibody (BA1038; Boster, China) at a dilution of 1:1000 at RT for $1 \mathrm{~h}$. The antibodyantigen complexes were detected using Western blotting luminal reagent. The bands on the film developed were quantified with the Quantity One 4.6.2 software (Bio-Rad, Hercules, CA, USA). The density of each Hsp60 protein band was normalized to that of GAPDH protein.

\section{Semiquantitative analysis of $h s p 60 \mathrm{mRNA}$ levels in vivo and in vitro by fluorescent quantitative polymerase chain reaction (qPCR)}

\section{Design of PCR primers}

PCR primers were designed according to each target mRNA using the Primer Premier 5.0 software. The ID numbers of the mRNA sequences obtained from the National Center for Biotechnology Information's GenBank are NM_022229.2 and NM_031144.3, respectively. The hsp60 primers were $h s p 60$ sense: 5'-CCGCCCCGCAGAAATGCTTCGA-3'; hsp60 antisense: 5'-AGGCTCGAGCATCCGCACCAA-3'. The expected size of the PCR product was $128 \mathrm{bp}$. The $\beta$-actin primers were $\beta$-actin sense: 5'-TGCGCAAGTTAGGTTTTGTCA-3'; $\beta$-actin antisense: 5'-GCAGGAGTACGATGAGTCCG-3'. The expected size of the PCR product was $110 \mathrm{bp}$.

\section{Isolation of total RNA and preparation of first strand $c D N A$}

Total RNA from rat heart tissues in vivo and rat myocardial cells in vitro from the control and heat stressed groups was isolated using RNAiso Plus (D9108A; Takara, China) following manufacturer protocols. The concentration of each RNA sample exceeded $1000 \mathrm{ng} / \mu \mathrm{L}$, with the optical density at $260 \mathrm{~nm}\left(\mathrm{OD}_{260}\right) / \mathrm{OD}_{280}$ ranging from 1.8 to 2.0. The RNA samples were reverse transcribed into cDNA using PrimeScript ${ }^{\mathrm{RT}}$ Master Mix Perfect Real Time (DRR036A; Takara) following the manufacturer protocol. Reaction products were stored at $-80^{\circ} \mathrm{C}$.

\section{Fluorescent qPCR}

Each cDNA sample ( $2 \mu \mathrm{L}, 10$ times dilution) was suspended in a total volume of 20 $\mu \mathrm{L}$ of the qPCR system with $10 \mu \mathrm{L}$ of $2 \mathrm{X}$ SYBR Premix Ex Taq (DRR041S; Takara, China), $0.6 \mu \mathrm{L}$ sense primer, $0.6 \mu \mathrm{L}$ antisense primer, and double-distilled water. qPCR was performed using a Bio-Rad IQ5 qPCR Thermocycler (IQ5; Bio-Rad, Hercules, CA, USA) following the manufacturer protocol. Briefly, enzyme activation was performed at $95^{\circ} \mathrm{C}$ for $3 \mathrm{~min}$, followed by 40 cycles of denaturation at $95^{\circ} \mathrm{C}$ for $20 \mathrm{~s}$, annealing at $60^{\circ} \mathrm{C}$ for $30 \mathrm{~s}$, and elongation at $72^{\circ} \mathrm{C}$ for $30 \mathrm{~s}$. For each run, a negative control without cDNA was analyzed along with the experimental samples, to ensure there was no gene pollution of the reaction system. A four-fold multiproportion dilution series of the cDNA was used in the qPCR to obtain standard curves as follows: $h s p 60$ mRNA: slope $=-3.43, r^{2}=0.998$; and $\beta$-actin mRNA: slope $=-3.49, r^{2}=0.998$. The amplification efficiencies of the target and reference were approximately equal. There- 
fore, the $h s p 60$ mRNA levels were normalized to $\beta$-actin mRNA using the following formula: Relative quantity of mRNA $=2^{-\Delta \Delta C t}$

$-\Delta \Delta C t=-\left\{\left[\left(C t_{\text {hspmRNA }}-C t_{\beta-\text { actinmRNA }}\right)\right.\right.$ heat stress group $]-\left[\left(C t_{\text {hspmRNA }}-C t_{\beta-a c t i n m R N A}\right)\right.$ control group $\left.]\right\}$ Statistical analysis

Statistical analysis of the differences between the heat stressed groups and the control groups were performed using Duncan's one-way analysis of variance with SPSS for Windows version 17.0. The results are reported as the means \pm standard deviation of at least 3 independent experiments. $\mathrm{P}<0.05$ was considered to be statistically significant.

\section{RESULTS}

\section{Clinical syndrome of experimental rats after heat stress}

As soon as the rats were moved from $25^{\circ} \mathrm{C}$ into the preheated chamber at $42^{\circ} \pm 1{ }^{\circ} \mathrm{C}$, all individuals began to exhibit polypnea and nervousness compared to the controls. After 20 $\mathrm{min}$ of heat stress, the rats were sweating, and their drinking volume had increased. The first deaths induced by heat stress occurred within $60 \mathrm{~min}$. Five percent of rats exposed to $60 \mathrm{~min}$ heat stress died, $20 \%$ of those exposed to $80 \mathrm{~min}, 50 \%$ of those exposed to $100 \mathrm{~min}$, and $100 \%$ of those exposed to $120 \mathrm{~min}$.

\section{Histo- and cytopathological changes induced by heat stress in rat myocardial cells in vivo and in vitro}

Histopathology showed acute degeneration induced by heat stress in the myocardial cells of rats in vivo (Figure 1). After 20 min of heat stress, the interstitial space between the muscle fibers was slightly enlarged in the hearts of the heat stressed rats compared to the control group. Granular degeneration characterized by cloudy cytoplasm in the myocardial fibers and obvious hyperemia in the blood capillaries was observed. The intercalated disc structure almost disappeared. After $40 \mathrm{~min}$, marked acute degeneration characterized by light pink staining of tiny granular particles and the loss of striations in the cytoplasm appeared in the myocardial fibers. After 60 and $80 \mathrm{~min}$, obvious granular degeneration and loss of striation were observed in the cytoplasm of swollen myocardial cells. After $100 \mathrm{~min}$, edema characterized by enlarged interstitial spaces between the muscle fibers and granular degeneration characterized by cloudy cytoplasm in swollen heart cells were observed. Throughout the period of heat stress, necrosis recognized by karyolysis in the myocardial fibers was occasionally observed.

Cytopathology showed acute degeneration induced by heat stress in the H9c2 myocardial cells in vitro (Figure 2). The cells had become rounder in shape and enlarged in size after 20 min of heat stress, with the appearance of granular particles in the cytoplasm of some swollen cells. After $40 \mathrm{~min}$, most of the cells had become rounded. Acute granular degeneration characterized by the light pink staining of tiny particles in the cytoplasm was observed. After $60 \mathrm{~min}$, the cells had become irregular in shape and extremely large. After $100 \mathrm{~min}$, obvious acute degeneration characterized by the light pink staining of tiny particles in the cytoplasm 
was observed, and necrotic cells characterized by karyolysis were occasionally observed.

\section{Expression of Hsp60 protein in rat heart tissues in vivo and rat myocardial cells in}

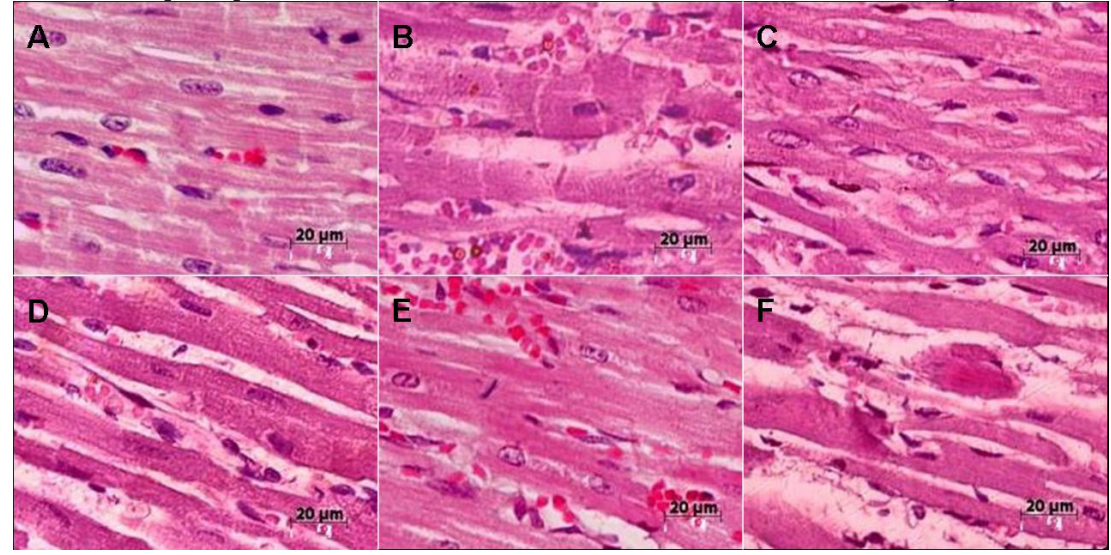

Figure 1. Representative histopathological images of rat myocardial cells in vivo. Hematoxylin and eosin staining. Scale bar $=20 \mu \mathrm{m}$. A. No obvious histopathological change was observed in the myocardial cells of control rats. B. After 20 min of heat stress, granular degeneration was observed, which was characterized by enlarged cell size and cloudy cytoplasm in the myocardial fibers and obvious hyperemia in the blood capillaries. C. After $40 \mathrm{~min}$, acute granular degeneration was observed in the myocardial fibers, with light pink staining and loss of striation in the cytoplasm. D. After $60 \mathrm{~min}$, granular degeneration was recognized by the presence of enlarged cells and edema characterized by increased interstitial spaces between muscle fibers. E. After 80 min, cloudy cytoplasm in swollen myocardial fibers and light hyperemia were observed. F. After $100 \mathrm{~min}$, necrosis was recognized by karyolysis in the myocardial fibers and obvious edema characterized by increased interstitial spaces between muscle fibers.

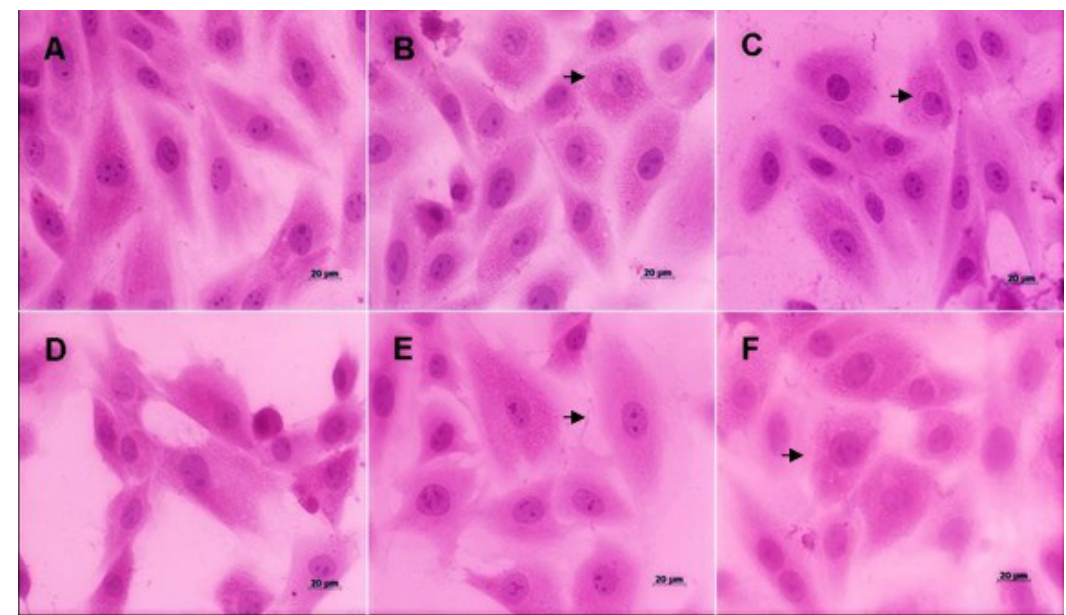

Figure 2. Representative cytopathological images of H9c2 rat myocardial cells in vitro. Hematoxylin and eosin staining. Scale $b a r=20 \mu \mathrm{m}$. A. No obvious cytopathological change was observed in normal H9c2 myocardial cells. B. After $20 \mathrm{~min}$ of heat stress, granular particles had appeared in the cytoplasm of some swollen myocardial cells. C. After $40 \mathrm{~min}$, most of the H9c2 cells had become rounder in shape. D. After 60, the cells had become irregular in shape. E. After $80 \mathrm{~min}$, the cells had become extremely large (arrow) compared with normal myocardial cells. F. After $100 \mathrm{~min}$ of heat stress, obvious acute degeneration characterized by light pink staining of tiny granular particles appeared in the cytoplasm of the H9c2 cells (arrow). 


\section{vitro on heat stress}

Hsp60 expression was detected in rat heart tissues in vivo and in rat myocardial cells in vitro from both the control and heat-stressed groups (Figure 3). Hsp60 protein expression (normalized to GAPDH protein levels) increased after heat stress in both the heart tissues and the myocardial cells, but varied in differing manners. After 20 min of heat stress, Hsp60 protein expression in the heart tissues in vivo increased dramatically $(\mathrm{P}<0.01)$ compared to that in the control group, with these higher levels being maintained until $80 \mathrm{~min}(\mathrm{P}<0.01)$. At $100 \mathrm{~min}$, Hsp60 expression in the heart tissues was reduced compared to the control group. In H9c2 myocardial cells, Hsp60 expression was constitutively expressed under both normal conditions and heat stress. Significant induction of Hsp60 in vitro began from $80 \mathrm{~min}(\mathrm{P}<0.05)$; however, there was a slight increasing tendency from the beginning of heat stress $(\mathrm{P}>0.05)$.

\section{Transcription of $h \operatorname{sp60} \mathrm{mRNA}$ in rat heart tissues in vivo and rat myocardial cells}
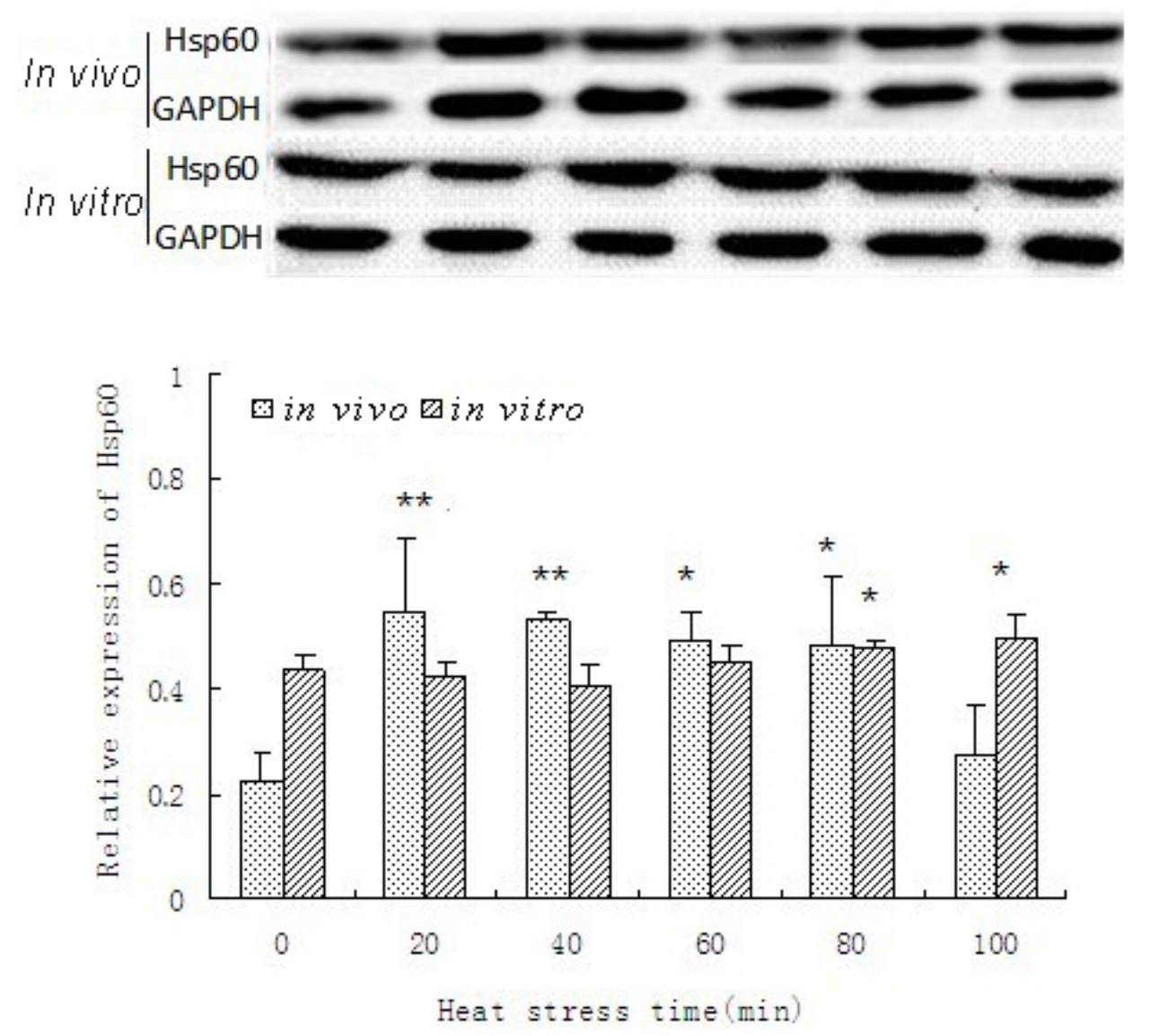

Figure 3. Changes in Hsp60 levels in rat heart tissues in vivo and rat myocardial cells in vitro with increasing duration of heat stress. $* \mathrm{P}<0.05$ and ${ }^{* *} \mathrm{P}<0.01$ compared to the controls. Values are reported as means \pm standard deviation. 


\section{in vitro on heat stress}

Hsp60 mRNA transcription was detected in rat heart tissues in vivo and rat myocardial cells in vitro from both the control and the heat stressed groups (Figure 4). The transcription of $h s p 60$ mRNA was normalized to $\beta$-actin mRNA levels. Compared to the control group, the transcription of hsp 60 mRNA had decreased at 20 min of heat stress; however, the difference was not significant $(\mathrm{P}>0.05)$. A dramatic increase in $h s p 60 \mathrm{mRNA}$ transcription started at 100 min compared to the control group $(\mathrm{P}<0.01)$. The transcription of $h s p 60$ mRNA in rat myocardial cells in vitro showed a tendency to be induced from 20 to $40 \mathrm{~min}$; however, the differences were not significant $(\mathrm{P}>0.05)$ compared to the control group. $h s p 60 \mathrm{mRNA}$ transcription in the myocardial cells significantly increased $(\mathrm{P}<0.05)$, and was maintained at a higher level, after $60 \mathrm{~min}$. The highest level of $h s p 60 \mathrm{mRNA}$ transcription was observed at 100 min. In both heart tissues in vivo and myocardial cells in vitro, hsp60 mRNA transcription in the heat stressed groups was greatest at $100 \mathrm{~min}$.

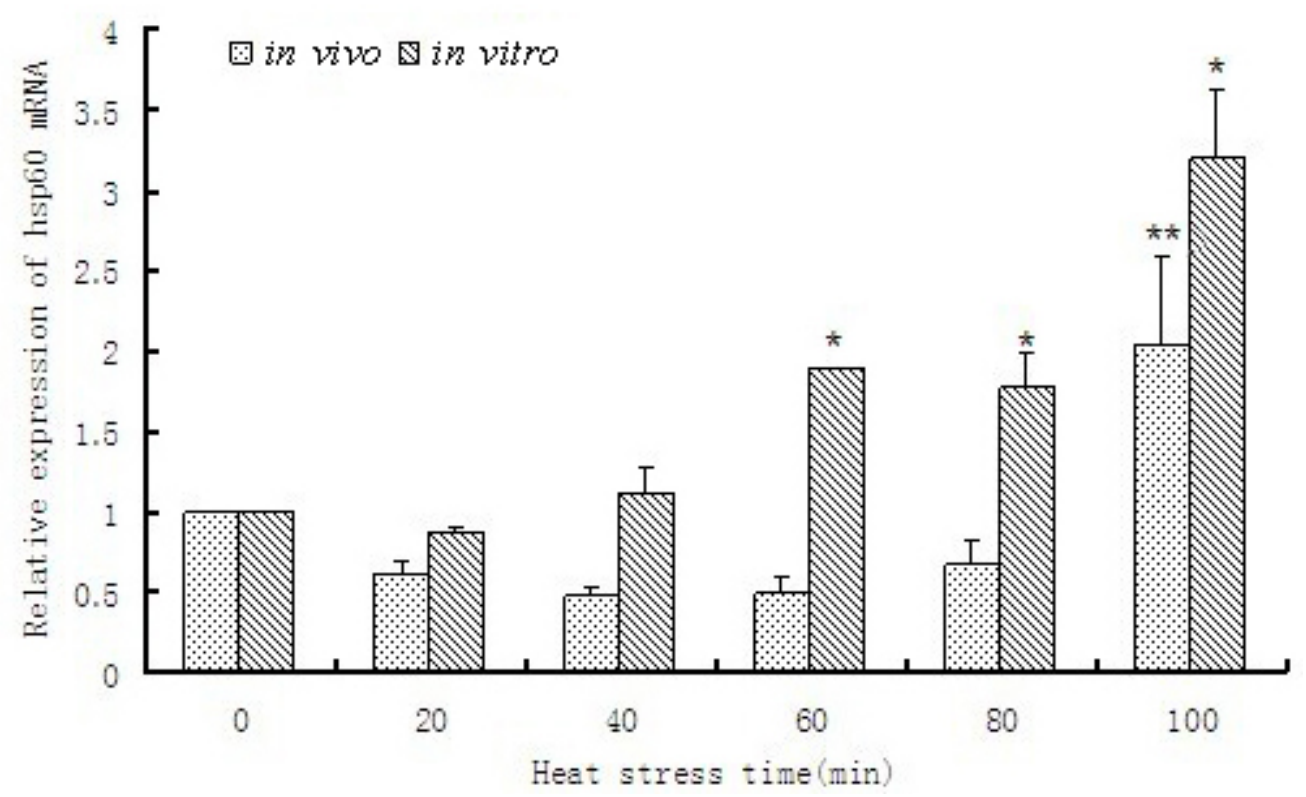

Figure 4. Changes in hsp60 mRNA transcription in rat heart tissues in vivo and rat myocardial cells in vitro with increasing duration of heat stress. $* \mathrm{P}<0.05$ and $* * \mathrm{P}<0.01$ compared to the controls. Values are reported the means \pm standard deviation.

\section{DISCUSSION}

Extremely high temperature causes eventual sudden death in heat stressed rats in vivo. In the present study, almost all of the heat stressed rats were dead within $2 \mathrm{~h}$ after the start of heat stress. This finding was not entirely consistent with that previously reported for chickens, in which the death rate was more than $50 \%$ when the environmental temperature was higher than $40^{\circ} \mathrm{C}$ for 2-3 h. Some chickens remained alive, even after heat stress for $5 \mathrm{~h}$ (Yan et al., 
2009). This difference may be due to the differing physiologies of mammals and birds. Histopathologically, we observed granular degeneration in heart tissues from the onset of heat stress. However, while $50 \%$ of the rats died within $100 \mathrm{~min}$, no obvious necrotic myocardial cells were observed. This finding suggests that the acute degeneration of myocardial cells, without necrosis, is sufficient to cause sudden death in animals. Previous studies showed that sudden death in response to high environmental temperature may arise from acute failure of various organs, such as the heart, kidney and liver (Bouchama and Knochel, 2002), with cardiac failure alone increasing the risk of sudden death five-fold (Kannel et al., 1988). Heart failure affects the mitochondrial but not myofibrillar properties of skeletal muscle (De Sousa et al., 2000). However, the particular mechanism of heat stress that induces sudden death remains to be confirmed.

As a mitochondrial protein, Hsp60 is a potential biomarker of heat stress, and may protect against hyperthermia induced myocardial cellular damage both in vivo and in vitro. In the present study, Hsp60 expression was detected in both rat heart tissues in vivo and rat myocardial cells in vitro under heat stress conditions. Hsp60 was constitutively expressed in the myocardial cells both in vivo and in vitro, with Hsp60 expression gradually and significantly increasing under heat stress. Many previous studies have also observed this pattern (Kammenga et al., 1998; Lewis et al., 1999). Hsp60 expression significantly increased in rat heart tissues after just 20 min of heat stress in vivo, indicating that myocardial cells respond to heat stress as soon as it occurs, and increase the production of Hsp60 to protect against further stress. This hypothesis supports the findings of previous studies, whereby Hsp60 may serve as an early trigger for myocyte loss and the progression of heart failure (Gullo and Teoh, 2004). The overexpression of Hsp60 may explain the increased requirement for ATP under heat stress in the heart, due to an increased rate of heart contraction (Koelkebeck and Odom, 1995), and provides strong support for the role of Hsp60 protein in thermo-tolerance (Sharma et al., 2006). However, many of the experimental rats in the present study died during heat stress, despite the induction of Hsp60 in their heart tissues in vivo, indicating that the rats continued to suffer injury, and that Hsp60 is inadequate for the protection of heart tissue from extreme heat stress. Nevertheless, Hsp60 may potentially be used as a biomarker in the diagnosis and prognosis of heat stress damage, in addition to assessing response to treatment. It has been previously reported that Hsp60 has a potential role as a biomarker in cardiovascular disease (Rizzo et al., 2011).

Changes in Hsp60 expression in H9c2 rat myocardial cells in vitro were inconsistent with those in rat heart tissues in vivo. Our preliminary results show that the histopathological damage caused by heat stress differed between heart tissues and myocardial cells, as did the expression of Hsp60. From 20 to 60 min of heat stress, no significant changes were observed in the expression of Hsp60 in heat stressed H9c2 myocardial cells. According to published data, Hsp60 protein may be transported from the cytoplasm to mitochondria or membrane to intracellular sites (Koll et al., 1992; Soltys and Gupta, 1997). It has been reported that Hsp60 markedly decreases in the kidney papilla of rats that are water restricted, whereas the protein increases in the mitochondria of the kidney papilla (Itoh et al., 2002). In the present study, significant induction of Hsp60 expression only occurred at $80 \mathrm{~min}$ after the onset of heat stress in H9c2 myocardial cells in vitro, whereas Hsp60 expression significantly increased after just 20 min in heart tissue in vivo. This difference may reflect the degree of injury sustained by myocardial cells in vivo and in vitro. The results indicate that the overexpression of Hsp60 in rat myocardial cells in vitro is delayed, or that a more complicated regulatory mechanism is involved in the response to high temperature of myocardial cells in vivo. The detailed mecha- 
nism remains unclear.

hsp60 mRNA levels increased under heat stress both in vivo and in vitro. The induction of heat shock proteins is largely regulated at the transcriptional level (Kaarniranta et al., 2002). However, in the present study, the transcription of hsp60 mRNA in heat stressed rat myocardial cells differed in vivo and in vitro. H9c2 cell transcription in vitro had increased significantly after $60 \mathrm{~min}$ of heat stress, whereas transcription in heart tissues in vivo only increased by $100 \mathrm{~min}$; i.e., about $40 \mathrm{~min}$ later. This result is partly consistent with a previous finding that heat stress promotes the transcription of heat shock protein genes (Sorger and Pelham, 1988). The difference between hsp60 mRNA transcription in vivo and in vitro may arise because of the physiological accommodation at the organ and/or system level in vivo. Variation in Hsp60 levels did not correspond with changes in hsp60 mRNA levels in the heart tissues of rats in vivo under heat stress. This observation is not consistent with the classic regulatory mechanisms that link transcription and translation. However, in the H9c2 myocardial cell line in vitro, the expression profiles of Hsp60 at the mRNA and protein levels were strongly concordant with each other, with this finding being consistent with observations of hemocytes (Cui et al., 2010). This result might be due to physiological accommodation; however, the detailed mechanism requires further study.

\section{ACKNOWLEDGMENTS}

Research supported by the National Key Basic Research Program of China ("973" Program) (\#2014CB138502), the National Natural Science Foundation of China (\#30972165), the National Department Public Benefit Research Foundation (Agriculture) (\#201003060-11), the Project Fund by the Priority Academic Program Development of Jiangsu Higher Education Institutions (PAPD), and the Sino-German Agricultural Cooperation Project of the Federal Ministry of Food, Agriculture and Consumer Production, Berlin, Germany.

\section{REFERENCES}

Barisic K and Kopic J (2002). Heat shock proteins and their clinical relevance. Acta Pharm. 52: 71-82. Bouchama A and Knochel JP (2002). Heat stroke. New Engl. J. Med. 346: 1978-1988.

Bukau B and Horwich AL (1998). The Hsp70 and Hsp60 chaperone machines. Cell 92: 351-366.

Cui YD, Du YZ, Lu MX and Qiang CK (2010). Cloning of the heat shock protein 60 gene from the stem borer, Chilo suppressalis, and analysis of expression characteristics under heat stress. J. Insect Sci. 10: 100.

De Sousa E, Veksler V, Bigard X, Mateo P, et al. (2000). Heart failure affects mitochondrial but not myofibrillar intrinsic properties of skeletal muscle. Circulation 102: 1847-1853.

Ewalt KL, Hendrick JP, Houry WA and Hartl FU (1997). In vivo observation of polypeptide flux through the bacterial chaperonin system. Cell 90: 491-500.

Fayet O, Ziegelhoffer T and Georgopoulos C (1989). The groES and groEL heat shock gene products of Escherichia coli are essential for bacterial growth at all temperatures. J. Bacteriol. 171: 1379-1385.

Geraert PA, Padilha JC and Guillaumin S (1996). Metabolic and endocrine changes induced by chronic heat exposure in broiler chickens: biological and endocrinological variables. Br. J. Nutr. 75: 205-216.

Gullo CA and Teoh G (2004). Heat shock proteins: to present or not, that is the question. Immunol. Lett. 94: 1-10.

Itoh $\mathrm{H}$, Komatsuda A, Ohtani H, Wakui H, et al. (2002). Mammalian HSP60 is quickly sorted into the mitochondria under conditions of dehydration. Eur. J. Biochem. 269: 5931-5938.

Kaarniranta K, Oksala N, Karjalainen HM, Suuronen T, et al. (2002). Neuronal cells show regulatory differences in the hsp70 gene response. Brain Res. Mol. Brain Res. 101: 136-140.

Kammenga JE, Arts MSJ and Oude-Breuil WJM (1998). HSP60 as a potential biomarker of toxic stress in the nematode plectus acuminatus. Arch. Environ. Contam. Toxicol. 34: 253-258. 
Kannel WB, Plehn JF and Cupples LA (1988). Cardiac failure and sudden death in the Framingham Study. Am. Heart J. 115: 869-875.

Koelkebeck KW and Odom TW (1995). Laying hen responses to acute heat stress and carbon dioxide supplementation: II. Changes in plasma enzymes, metabolites and electrolytes. Comp. Biochem. Physiol. A Physiol. 112: 119-122.

Koll H, Guiard B, Rassow J, Ostermann J, et al. (1992). Antifolding activity of hsp60 couples protein import into the mitochondrial matrix with export to the intermembrane space. Cell 68: 1163-1175.

Lee WC, Lin KY, Chiu YT, Lin JH, et al. (1996). Substantial decrease of heat shock protein 90 in ventricular tissues of two sudden-death pigs with hypertrophic cardiomyopathy. Faseb J. 10: 1198-1204.

Lewis S, Handy RD, Cordi B, Billinghurst Z, et al. (1999). Stress proteins (Hsp's): Methods of detection and their use as an environmental biomarker. Ecotoxicology 8: 351-368.

Lin L, Kim SC, Wang Y, Gupta S, et al. (2007). HSP60 in heart failure: abnormal distribution and role in cardiac myocyte apoptosis. Am. J. Physiol. Heart Circ. Physiol. 293: H2238-H2247.

Pockley AG, Wu R, Lemne C, Kiessling R, et al. (2000). Circulating heat shock protein 60 is associated with early cardiovascular disease. Hypertension 36: 303-307.

Rizzo M, Macario AJ, de Macario EC, Gouni-Berthold I, et al. (2011). Heat shock protein-60 and risk for cardiovascular disease. Curr. Pharmaceut. Des. 17: 3662-3668.

Rizzo M, Cappello F, Marfil R, Nibali L, et al. (2012). Heat-shock protein $60 \mathrm{kDa}$ and atherogenic dyslipidemia in patients with untreated mild periodontitis: a pilot study. Cell Stress Chaperones 17: 399-407.

Sharma S, Reddy PVJ, Singh Rohilla M, Tiwari PK (2006). Expression of Hsp60 homologue in sheep blowfly Lucilia cuprina during development and heat stress. J. Therm. Biol. 31: 546-555.

Snoeckx LH, Cornelussen RN, van Nieuwenhoven FA, Reneman RS, et al. (2001). Heat shock proteins and cardiovascular pathophysiology. Physiol. Rev. 81: 1461-1497.

Soltys BJ and Gupta RS (1997). Cell surface localization of the 60-kDa heat shock chaperonin protein (hsp60) in mammalian cells. Cell Biol. Int. 21: 315-320.

Sorger PK and Pelham HRB (1988). Yeast heat shock factor is an essential DNA-binding protein that exhibits temperaturedependent phosphorylation. Cell 54: 855-864.

Tissières A, Mitchell HK and Tracy UM (1974). Protein synthesis in salivary glands of Drosophila melanogaster: relation to chromosome puffs. J. Mol. Biol. 84: 389-398.

van der Hel W, Verstegen MW, Pijls L and van Kampen M (1992). Effect of two-day temperature exposure of neonatal broiler chicks on growth performance and body composition during two weeks at normal conditions. Poultry Sci. 71: 2014-2021.

Walter S and Buchner J (2002). Molecular chaperones - cellular machines for protein folding. Angew. Chem. Int. Ed. Engl. 41: 1098-1113.

Yan J, Bao E and Yu J (2009). Heat shock protein 60 expression in heart, liver and kidney of broilers exposed to high temperature. Res. Vet. Sci. 86: 533-538. 